Société d'histoire de la révolution de 1848 et des

révolutions du XIXe siècle

Savoirs occultés : du magnétisme à l'hypnose

\title{
Lynn L. SHARP,Secular Spirituality. Reincarnation and Spiritism in Nineteenth-Century France
}

Lanham, Lexington Books, 2006, 244 p. ISBN: 978-0739113394.

28,95 dollars

Guillaume Cuchet

\section{(2) OpenEdition}

Journals

Édition électronique

URL : http://journals.openedition.org/rh19/3896

DOI : $10.4000 /$ rh 19.3896

ISSN : $1777-5329$

Éditeur

La Société de 1848

Édition imprimée

Date de publication : 1 juillet 2009

Pagination : 156-158

ISSN : 1265-1354

Référence électronique

Guillaume Cuchet, « Lynn L. SHARP,Secular Spirituality. Reincarnation and Spiritism in Nineteenth-Century France », Revue d'histoire du XIXe siècle [En ligne], 38 | 2009, mis en ligne le 05 juillet 2009, consulté le 22 septembre 2020. URL : http://journals.openedition.org/rh19/3896 ; DOI : https://doi.org/10.4000/ rh19.3896

Ce document a été généré automatiquement le 22 septembre 2020

Tous droits réservés 


\section{Lynn L. SHARP, Secular Spirituality. Reincarnation and Spiritism in Nineteenth-Century France}

Lanham, Lexington Books, 2006, 244 p. ISBN: 978-0739113394.

28,95 dollars

\section{Guillaume Cuchet}

1 Les sondages sur les croyances des Français montrent régulièrement qu'ils sont plus nombreux à croire à la réincarnation qu'à la résurrection des corps dont Saint Paul disait pourtant qu'elle était la pierre de touche du christianisme. On conviendra que même dans une société postchrétienne comme la nôtre, le phénomène a de quoi surprendre. Spontanément, on serait tenté de le mettre sur le compte des grandes ruptures culturelles et religieuses des années 1960, de la mode des religions orientales, du new age, voire de la popularité du Dalaï-lama, mais un des mérites du livre de Lynn L. Sharp est de nous rappeler que la croyance à la réincarnation en France est une vieille histoire et que, d'une certaine façon, le terrain du new age était préparé de longue date.

2 L'idée remonte au moins au XVIII ${ }^{\mathrm{e}}$ siècle. On la retrouve au XIX ${ }^{\mathrm{e}}$ siècle dans toute une partie du courant romantique et socialiste, chez un Fourier, un Jean Reynaud, un Pierre Leroux. Sous le Second Empire, avec la naissance du spiritisme d'Allan Kardec, elle touche un large public. Dans le Livre des Esprits (1857), la bible du spiritisme jusqu'à nos jours, Kardec reprend à son compte la version de la réincarnation élaborée par l'ancien saint-simonien Jean Reynaud. Celui-ci prétendait qu'elle remontait en France aux druides gaulois et qu'elle n'était donc pas une nouveauté ou un produit d'importation oriental. En nationalisant le concept, Reynaud puis Kardec (qui se prenait lui-même pour la réincarnation d'un druide) présentaient le ralliement à cette croyance comme une façon pour les Français de rentrer dans un héritage refoulé par des siècles de christianisme.

3 L'auteur, qui travaille depuis longtemps sur le sujet, apporte des précisions intéressantes sur la chronologie du mouvement, sa diversité et son évolution. Elle 
considère que le sommet de la vague est atteint vers 1870, avant la guerre francoprussienne et la Commune. Au-delà commence une décennie difficile qui se termine au seuil des années 1880. Comme l'avait déjà montré Nicole Edelman, le mouvement repart ensuite tout en se divisant: derrière Pierre-Gaëtan Leymarie, le successeur de Kardec à la tête de la Revue spirite, s'affirme un courant plus politique; derrière Gabriel Delanne, un courant à prétentions plus «scientifiques»; derrière Léon Denis, un courant plus religieux. Avec le temps, des traditions se constituent et l'on voit apparaitre la deuxième puis la troisième génération de spirites. Alors que Léon Denis, par exemple, s'est converti au spiritisme à 18 ans en lisant le Livre des Esprits, Gabriel Delanne et Paul Leymarie, fils de spirites éminents, sont «nés dedans» (ce qui permet peut-être de comprendre accessoirement qu'ils soient plus sensibles aux dimensions extrareligieuses du phénomène). L'auteur souligne que dans la période 1880-1914, le climat se transforme avec le développement des nouvelles sciences de la psyché (psychologie, psychiatrie, psychanalyse) et le succès de l'occultisme, plus aristocratique dans sa clientèle, qui «ringardise» le spiritisme. Elle montre par exemple que sa place décline entre les deux congrès spirites et spiritualistes internationaux qui se tiennent à Paris en 1889 et en 1900.

4 L'ouvrage rappelle (fait souvent négligé) à quel point le socialisme prémarxiste en France et le parti républicain lui-même étaient encore profondément marqués par le spiritualisme «quarante-huitard» dans les années 1850-1870. Le livre de Frank Paul Bowman sur les idées religieuses des "quarante-huitards» ${ }^{1}$, en s'arrêtant à la fin de la Seconde République, avait l'inconvénient de donner à penser qu'après sa chute elles s'étaient effacées en même temps que leurs espérances politiques. Or en réalité non seulement elles n'ont pas disparu mais elles n'ont probablement jamais été aussi populaires que sous le Second Empire. Beaucoup d'hommes et de femmes de gauche se sont repliés sur le terrain religieux après le coup d'État, parfois dès juin 1848 comme George Sand, pour se consoler, pour s'occuper tout simplement ou pour faire de la politique sans trop en avoir l'air dans un domaine où, même sous l'Empire autoritaire, la discussion restait relativement libre. Le spiritisme a contribué largement à cette diffusion, entre autres parce qu'à partir du moment où les tables se sont mises à «parler» et qu'on leur a posé des questions sur l'au-delà, tous ces systèmes philosophico-religieux conçus dans la première moitié du siècle ont trouvé une nouvelle utilité et un large public.

5 Le livre a un autre intérêt: celui d'attirer l'attention sur la nébuleuse spiritualiste du XIX ${ }^{\mathrm{e}}$ siècle, ce vaste «diocèse» (pour reprendre le mot de Sainte-Beuve à propos de la libre pensée) qui rassemblait tous ceux qui ne croyaient pas ou plus au dogme catholique mais qui n'avaient pas renoncé pour autant à toute croyance religieuse. Alors que certains se contentaient d'un spiritualisme réduit à l'affirmation de l'existence de Dieu et à l'immortalité de l'âme, d'autres aspiraient à plus de précision dogmatique. D'où le succès de ces nouvelles religions que l'auteur appelle des «spiritualités séculières» qui ont constitué pour beaucoup des alternatives crédibles au catholicisme. Sait-on par exemple qu'un Maurice Lachâtre, l'éditeur d'Eugène Sue et du Capital de Marx, était lui-même un spirite convaincu, tout comme le fouriériste JeanBaptiste Godin, fondateur du familistère de Guise, ou bon nombre de membres de la Ligue de l'enseignement de Jean Macé?

6 Pourquoi n'avoir pas parlé davantage de l'évolution des conceptions de la mort et du rapport aux défunts au XIX ${ }^{\mathrm{e}}$ siècle? De l'aveu même de Kardec, deux spirites sur trois 
venaient à sa doctrine pour cause de deuils compliqués. Le fait que le spiritisme se soit développé au moment où le «culte des morts» triomphe dans la société française et où la dévotion aux âmes du purgatoire connait un formidable renouveau dans le catholicisme n'est pas un hasard.

7 Si l'auteur souligne avec raison l'importance de ces «spiritualités séculières» dans l'histoire philosophique de la gauche française, c'est moins vrai, me semble-t-il, après 1870. Quelque chose se brise ici dès le milieu des années 1860, avant même 1870. C'est sensible à la lecture de la Revue spirite: le ton euphorique des années 1860-1863 disparaît et Kardec, comme d'autres spiritualistes de gauche de sa génération, est sur la défensive. À gauche, le renouveau des idées positivistes et matérialistes et le changement de génération vont refouler progressivement ce genre de spéculations dans le hangar des vieilles lunes. Un Léon Denis, de ce point de vue, fait quelque peu figure d'attardé sous la Troisième République.

Dernière question: peut-on vraiment parler de «religion populaire urbaine» pour désigner le spiritisme, même dans ses années de prospérité maximale? Certes, il existe un noyau consistant de fervents et de convertis pour qui il s'agit bien d'une espèce de religion. Mais pour la masse de ses consommateurs intermittents, qui restent le plus souvent nominalement catholiques, il s'agit sans doute davantage d'une sorte de croyance parallèle qui vient non pas remplacer mais pallier les insuffisances de la religion traditionnelle. 